\title{
ROLE OF ECHOCARDIOGRAPHY IN ATRIAL FIBRILLATION
}

\author{
TAE-SEOK KIM, MD AND HO-JOONG YOUN, MD, PHD \\ DIVISION OF CARDIOLOGY, DEPARTMENT OF INTERNAL MEDICINE, COLLEGE OF MEDICINE, \\ THE CATHOLIC UNIVERSITY OF KOREA, SEOUL, KOREA
}

Atrial fibrillation (AF) is most common arrhythmia and its prevalence appears to be increasing as the population ages. Echocardiography can play a key role in risk stratification and management of patients with AF. Transthoracic echocardiography allows rapid and comprehensive assessment of cardiac anatomical structure and function. Pulmonary vein flow monitoring using echocardiography has the potential to an increasing role in the evaluation of cardiac function and AF ablation procedures. Transesophageal echocardiography also provides accurate information about the presence of a thrombus in the atria and thromboembolic risk. The novel technique of intracardiac echocardiography has emerged as a popular and useful tool in the everyday practice of interventional electrophysiology. Other imaging modalities, such as computed tomography and magnetic resonance imaging have complementary roles in risk stratification and assessment of patients with AF. Echocardiography continues to be the foundation of clinical evaluation and management of AF.

KEY WORDS: Atrial fibrillation · Transthoracic echocardiography · Transesophageal echocardiography.

\section{INTRODUCTION}

Atrial fibrillation (AF) is the most frequently encountered arrhythmia in clinical practice, with an overall prevalence of $0.4 \%$ in the general population. ${ }^{1)}$ The prevalence of AF increases with age, occurring in $3.8 \%$ of people age 60 years and older and in up to $9 \%$ of people over 80 -year-of-age. ${ }^{23)}$ As the proportion of the elderly in many societies continues to increase, the number of patients with AF will likely increase. AF is associated with the significant clinical problems of systemic thromboembolism and hemodynamic deterioration. Quality of life and exercise capacity are also impaired in patients with AF. Data from the Framingham Heart Study suggest that the presence of AF is associated with a near doubling of both overall and cardiovascular mortality. ${ }^{4)}$ Advances in imaging technology and in the understanding of the pathophysiology of AF are leading to more definitive and potentially curative therapeutic approaches. Among the various diagnostic tools, echocardiography has an important role in the evaluation of cardiac structure and function and risk stratification in AF. Twodimensional (2D) and Doppler study using transthoracic echocardiography (TTE) should be performed for the initial workup of all patients with AF, in order to acquire informa- tion about left atrium (LA) and left ventricle (LV) size and function, and the presence of valvular, myocardial, pericardial and congenital heart disease which may predispose to AF. Echocardiography has also become an essential part of the guidelines for management of patients with $\mathrm{AF}^{5)}$ especially in elucidating the mechanisms of systemic thromboembolism in AF. Recently, the development of intracardiac echocardiography (ICE) has allowed the real-time guidance of percutaneous interventions, including radiofrequency catheter ablation (RFCA) of foci in the pulmonary veins (PV) and left atrial appendage (LAA) closure procedures for patients with AF. In this article, we review the role of echocardiography in the evaluation and management of patients with AF.

\section{EVALUATION OF LA SIZE AND FUNCTION IN AF}

\section{ANATOMICAL ASSESSMENT OF LA}

TTE is a reliable method to assess the anatomy of the LA. The measurement of LA anteroposterior diameter from Mmode echocardiography in the parasternal long-axis or shortaxis window is commonly utilized in clinical work. This conventional method has a tendency to underestimate true LA

- Received: March 21, $2011 \cdot$ Revised: May 7, $2011 \cdot$ Accepted: May 25, 2011

- Address for Correspondence: Ho-Joong Youn, Division of Cardiology, Department of Internal Medicine, Seoul St. Mary's Hospital, College of Medicine, The Catholic University of Korea, 505 Banpo-dong, Seocho-gu, Seoul 137-701, Korea Tel: +82-2-2258-1101, Fax: +82-2-2258-1103, E-mail: younhj@catholic.ac.kr - This is an Open Access article distributed under the terms of the Creative Commons Attribution Non-Commercial License (http://creativecommons.org/licenses/by-nc/3.0) which permits unrestricted non-commercial use, distribution, and reproduction in any medium, provided the original work is properly cited. 
size, because the shape of the LA is not spherical and enlargement of the LA is often asymmetrical. $\left.{ }^{6}\right)$ Hence, 2D derived LA volume assessment using the biplane area-length method or the Simpson's method provides more accurate measures of LA size.") A horizontal line needs to be drawn across the mitral annular plane, and the LA area does not include the funnel of the mitral valve leaflets (Fig. 1). When tracing the outline of the LA, the LAA and the confluence of the PVs are excluded from the measurement. The reference value for $2 \mathrm{D}$ echocardiographic maximum LA volume indexes is $\left.22 \pm 6 \mathrm{~mL} / \mathrm{m}^{2} .788\right)$ A LA volume index of $29 \mathrm{~mL} / \mathrm{m}^{2}$ is usually considered the upper limits of the normal value. ${ }^{7)}$ More recently, three-dimensional (3D) echocardiography for assessing LA volume has been available and has demonstrated good correlation with biplane 2D measurements." However, studies on 3D echocardiographic measurement of LA volume have been too small, and there is no consensus on the methods or comparisons with established normal values. LA size has been established as a prognostic marker for both adverse cardiovascular events as well as overall outcomes. ${ }^{10-12)}$ According to the data from the Framingham study, a 5-mm increase in LA dimension was associated with a $39 \%$ increased risk for subsequent development of $A F .{ }^{4)}$ Psaty et al. ${ }^{13)}$ demonstrated that subjects in sinus rhythm with a LA dimension over $5.0 \mathrm{~cm}$ had about four times the risk of developing AF during the following period of surveillance. Increased LA volume, likewise LA dimension, is predictive of subsequent $\mathrm{AF}^{11}$ and it has been confirmed that LA volume is a superior measure over LA dimension for predicting outcomes of $A F^{14)} \mathrm{LA}$ enlargement is associated with a low probability of successful cardioversion for chronic AF or maintenance of sinus rhythm. ${ }^{15116)}$ An increased LA volume index can predict recurrence of AF after RFCA. ${ }^{17)} \mathrm{Al}$ though AF promotes further LA enlargement, cardioversion and maintenance of sinus rhythm may reverse this process. Van Gelder et al. ${ }^{18)}$ reported that after restoration and longterm maintenance of sinus rhythm, echocardiographic atrial dimensions may decrease. Reant et al. ${ }^{19)}$ also demonstrated that RFCA for isolated AF reverse morphological remodeling of the LA after restoration of sinus rhythm.

\section{FUNCTIONAL ASSESSMENT OF LA}

In addition to providing information about atrial anatomy, echocardiography is also a potent tool for assessment of atrial function. With the loss of atrial booster pump function in $\mathrm{AF}$, the LA-LV pressure gradient during early LV filling is increased by elevation of the LA pressure to maintain stroke volume. ${ }^{20)}$ Thus, a reduction in both LA compliance and volume has been observed with the onset of $\mathrm{AF}$ that further decreases cardiac function and increases the risk of thromboembolism. The change of the LA function in different phases can be evaluated non-invasively by echocardiography, utilizing not only usual methods including transmitral flow and changes in LA area and volume, but also novel techniques such as tissue Doppler imaging (TDI) and strain imaging.

Transmitral inflow patterns by pulsed wave Doppler provides information of LA mechanical function. The peak transmitral inflow velocity of the late diastolic filling wave $(A)$ is commonly used as a measure of LA mechanical function, ${ }^{21)}$ but it cannot be measured in AF because of the absence of the atrial waveform. The peak A wave velocity has been used in the serial follow-up of LA function in patients with AF after cardioversion ${ }^{22)}$ and RFCA. ${ }^{23)}$ The time-velocity integral of the $\mathrm{A}$ wave and the atrial fraction (i.e., the ratio of the timevelocity integral of the mitral A wave to that of the total diastolic transmitral flow) may be used as a parameter of LA function. ${ }^{24)}$

TDI allows the quantification of the low-velocity, high-amplitude, long-axis intrinsic myocardial velocities in both systole and diastole, and provides a relatively load-independent measure of both LV systolic and diastolic function. ${ }^{25)}$ The peak velocity at the mitral annulus in late diastole, following atrial contraction ( $A^{\prime}$ or Aa velocity) can be utilized as a rapid and accurate marker of atrial function. ${ }^{26)}$ The $A^{\prime}$ velocity correlates with other parameters of atrial function such as peak A velocity

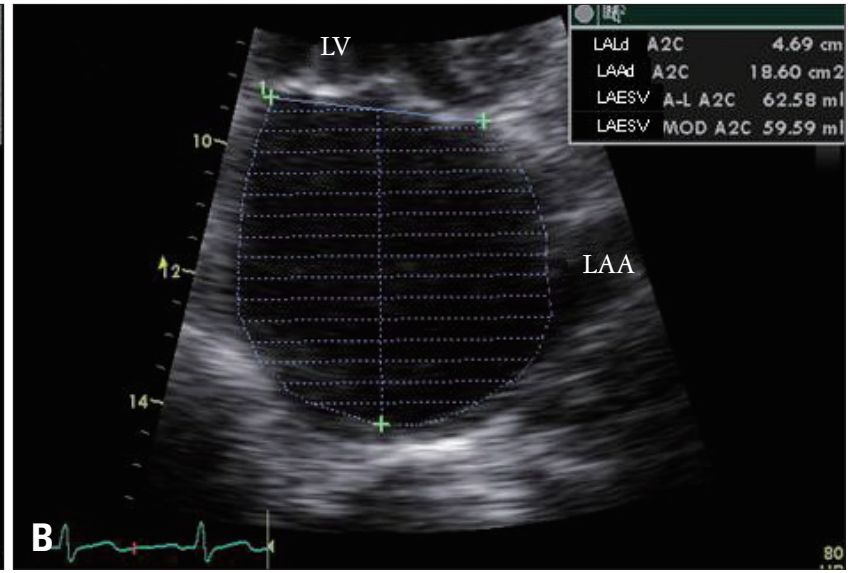

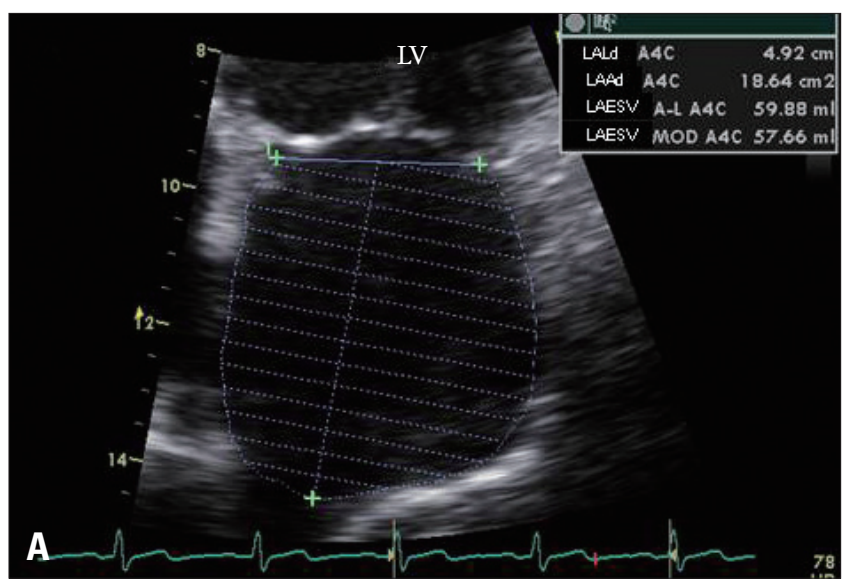

Fig. 1. Biplane left atrial (LA) volume measurement in apical 4 chamber (A) and apical 2-chamber (B) views of transthoracic echocardiography. LV: left ventricle, LAA: left atrial appendage. 
of mitral inflow, atrial fraction and atrial ejection force. ${ }^{26)} \mathrm{An}$ other study also demonstrated that the tissue Doppler A' velocity correlates with LA fractional area and volume change. ${ }^{27)}$

Doppler strain and strain rate imaging are derivatives of tissue Doppler velocities. TDI quantifies global tissue motion velocity whereas strain and strain rate represent the extent of local tissue deformation and its rate, respectively (Fig. 2). Strain measures the myocardial deformation during a cardiac cycle, and strain rate measures the tissue velocity gradient within the myocardium. Strain and strain rate imaging may overcome the major limitation of TDI, and may be largely independent of translational effects due to tethering by neighboring myocardial segments.

Using TDI and/or strain imaging techniques, it was found the decreased compliance of LA walls, the impairment of the reservoir and conduit function of LA, and the loss of the booster pump function in patients with $\mathrm{AF}^{28229)}$ With the degree of LA enlargement, LA mechanical dysfunction has emerged as an independent predictors for the maintenance of sinus rhythm after successful cardioversion ${ }^{29)}$ and RFCA. ${ }^{30)}$

Atrial stunning is characterized by reduced atrial mechanical function after restoration of sinus rhythm from AF, which may last several weeks and which is associated with increased risk of thromboembolism. This phenomenon is well recognized with peak A velocity of transmitral inflow ${ }^{2224)}$ as well as TDI or strain imaging. ${ }^{31)}$ This suggests that a dissociation of electrical and mechanical recovery occurs after successful restoration of sinus rhythm, with a delay in gradual improvement of atrial mechanical function.

These parameters, mentioned above, can only be easily measured in sinus rhythm and are often not applied to the state of AF. Other LA functional parameters, which are rhythm independent, have been recently suggested as being required. ${ }^{32)}$ More studies and trials to be accepted and validate these parameters are needed to use routinely in clinical practice.

\section{ASSESSMENT OF LV DIASTOLIC FUNCTION IN AF}

The presence and severity of diastolic dysfunction are associated with an increased risk for AF and heart failure in patients with sinus rhythm. Furthermore, the risk for heart failure is markedly increased once AF develops. ${ }^{33)}$ The evaluation of diastolic function in patients with AF has remained a clinical challenge, because the impairment of the LA mechanical function and the variable cycle lengths make the evaluation of diastolic function difficult. Several new methods have been intro-
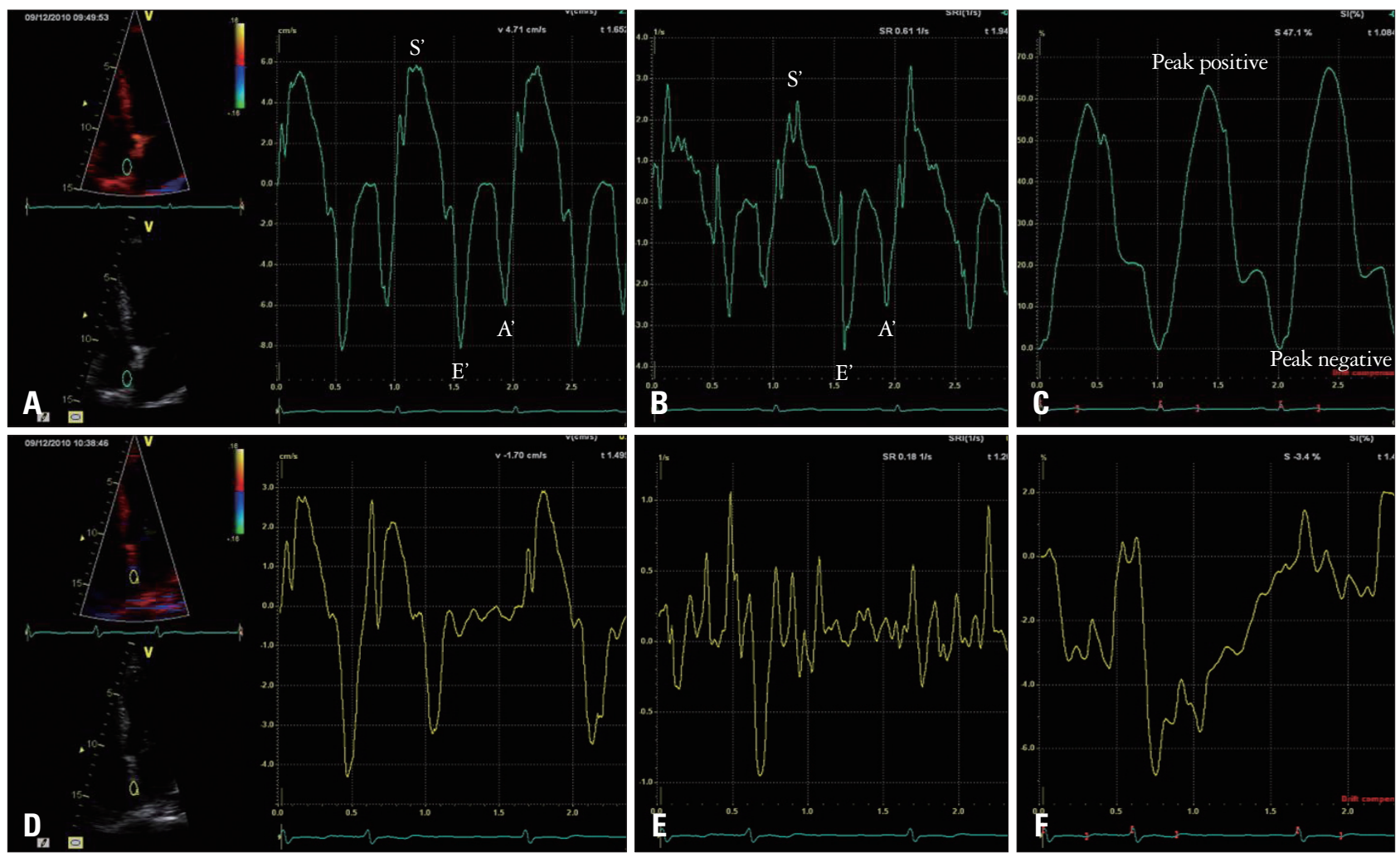

Fig. 2. Representative left atrial (LA) myocardial velocity using tissue Doppler image (TDI), strain rate (SR), and strain curves in a normal subject (A, $B$, and $C$, respectively) and a patient with atrial fibrillation (AF) (D, E, and F, respectively). The sample volume is placed at the mid-level of inter-atrial septum. In the patients with AF, no decrease in SR by atrial contraction was observed, but small phasic movements by the AF wave were recorded. Using TDI-derived velocity and SR parameters, it was found that the LA mechanical function was significantly decreased in AF as reflected by reduction in the S' and/or E' wave in the absence of the A' wave during late diastole. S' wave: ventricular systolic wave, E' wave: ventricular early diastolic wave, A' wave: late diastolic wave (atrial contraction). 


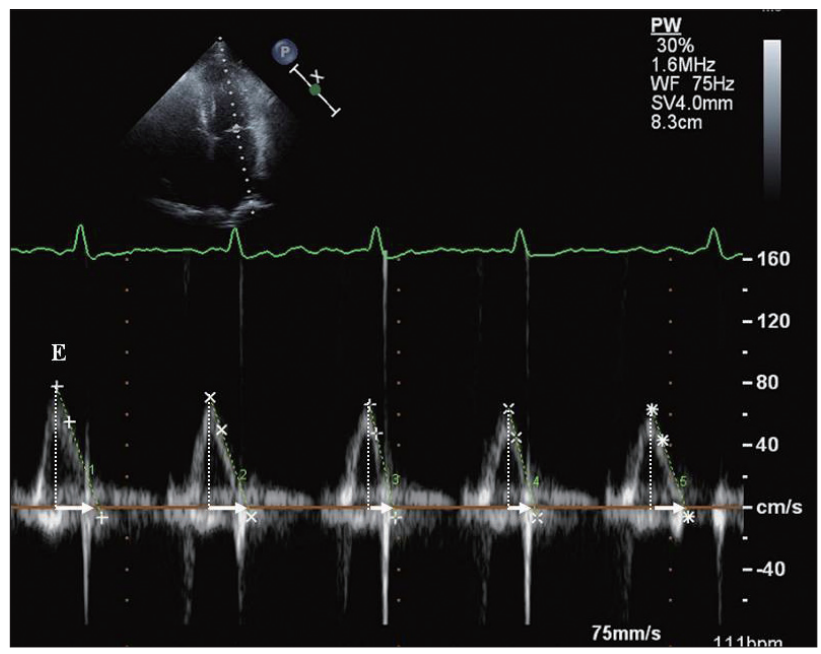

Fig. 3. Pulsed wave Doppler study of transmitral inflow in atrial fibrillation. Arrow indicates early transmitral flow deceleration time (DT). E represents peak LV early diastolic filling velocity. Peak E velocity and DT vary depending on cardiac cycle length. LV: left ventricle.

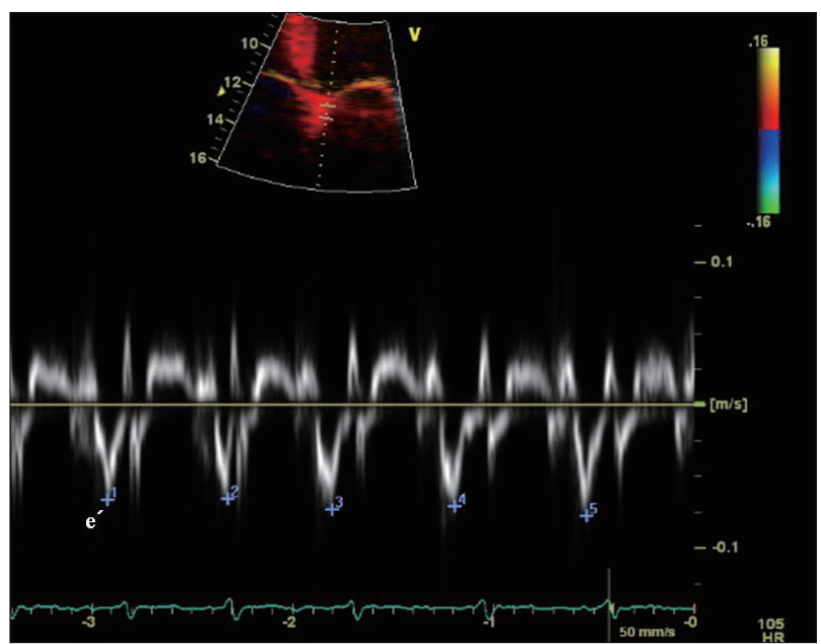

Fig. 4. Tissue Doppler imaging of the septal mitral annular velocities (e') in a patient with atrial fibrillation. The measurements should be averaged over 5 to 10 cardiac cycles.

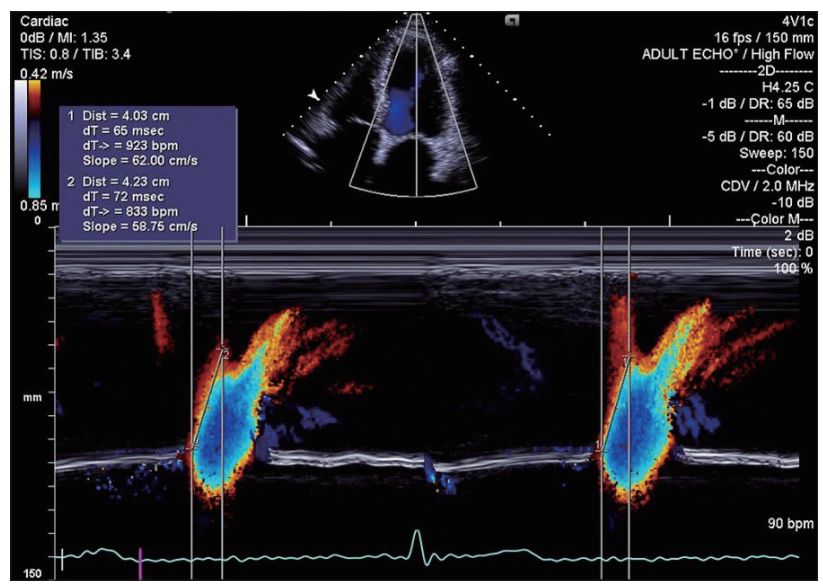

Fig. 5. Color M-mode, to calculate mitral inflow propagation velocity, is acquired from the apical 4-chamber view by placing a cursor over the center of mitral inflow and reducing the Nyquist limit for flow toward apex to a point when the central color turns blue. duced to be useful in measuring diastolic dysfunction of patients with AF. All echocardiographic parameters, which are obtained in the context of AF, should be measured and averaged from 5 to 10 cardiac cycles.

Early transmitral flow deceleration time (DT) provides relatively accurate assessment of LV diastolic function in the setting of AF. ${ }^{3435)}$ Matsukida et al. ${ }^{36)}$ demonstrated that a cutoff value of mitral DT $\leq 100 \mathrm{~ms}$ predicted a mean of pulmonary capillary wedge pressure (PCWP) $\geq 18 \mathrm{mmHg}$ with sensitivity of $80 \%$ and specificity $85 \%$. In AF, mitral flow measurements usually include peak LV early diastolic filling velocity (E) and DT over 5 to 10 cardiac cycles. A cycle length equivalent to a heart rate of 60 to 80 beats/min, with the interval $\geq 70$ ms between the end of transmitral inflow and the onset of the QRS complex, is preferred (Fig. 3). ${ }^{34)}$

Peak E velocity is dependent on LV relaxation and LA pressure. ${ }^{34)}$ To correct for LV relaxation, peak E velocity can be used as a ratio to the tissue Doppler early diastolic mitral annular motion velocity (e') (Fig. 4). TDI assessment of e' velocity is relatively independent of LA pressure. ${ }^{37)} \mathrm{E} / \mathrm{e}^{\prime}$ (septal) $>15$ and E/e' (lateral) > 10 have been shown to be highly specific for elevated LV filling pressure. ${ }^{3839)}$ The E/e' has been validated for LV diastolic filling pressure. ${ }^{40)}$

Color M-mode Doppler assessment of mitral inflow propagation velocity $(\mathrm{Vp})$ provides visualization of the temporal and spatial propagation flow along a single scan line from the annulus area to the LA apex throughout the diastolic period. A $\mathrm{Vp}<45 \mathrm{~cm} / \mathrm{s}$ is consistent with the presence of diastolic dysfunction (Fig. 5). ${ }^{41)}$

The isovolumic relaxation time (IVRT) is the time from the aortic valve closure to the onset of mitral inflow and has been shown to be a strong negative correlation with mean PCWP in AF. ${ }^{3435)}$ Increased IVRT is a marker of impaired LV relaxation and a shortened IVRT reflects the increased LV chamber stiffness. ${ }^{42)}$

There may be advantages to the use of regional strain rate imaging for assessment of diastolic function in patients with AF. In AF, there could be regional differences in diastolic filling depending on the LV response to the fibrillating atria. Therefore, regional strain rate imaging is expected to be a promising technique for assessing diastolic dysfunction in AF. However, more studies will be needed before its application to the clinical practice in patients with AF.

\section{PULMONARY VENOUS FLOW ASSESSMENT IN AF}

Pulmonary venous blood flow (PVF) exhibits a pulsatile behavior, which is related to LA pressure and function, mitral valve function, and LV compliance. Echocardiography helps to define characteristic flow patterns in AF. The disappearance of atrial reverse flow, a decrease in systolic flow with a greater diastolic than systolic flow, a prolonged onset of systolic flow and the appearance of an early systolic reverse flow are characteris- 
tic findings in AF. The disappearance of atrial reverse flow can be explained by the loss of active LA contraction. A decrease in systolic PVF has been also found to correspond closely to LAA dysfunction and spontaneous echo contrast (SEC) formation. ${ }^{43)}$ The change of PVF in AF seems to reflect a alteration in LA function, mainly atrial compliance, and reservoir function.

PVF pattern can be used as a monitoring tool for recovery of LA mechanical function after restoration of sinus rhythm with cardioversion or RFCA. Low systolic PVF obtained during AF (before cardioversion) ${ }^{44)}$ as well as obtained during sinus rhythm (immediately after cardioversion) ${ }^{45)}$ was associated with AF recurrence at 6 and 12 months after electrical cardioversion, respectively. In contrast, an early systolic PVF peak velocity $>57$ $\mathrm{cm} / \mathrm{s}$ predicted good mechanical function recovery with $96 \%$ specificity indicating that preserved reservoir function of LA during AF is predictive of satisfactory recovery of mechanical function after PV isolation. ${ }^{46)}$

Pulmonary venous diastolic DT is very useful to predict diastolic LV filling pressure, as estimated by PCWP in AF. ${ }^{47)}$ Pulmonary venous DT is calculated as the time between peak diastolic velocity and the upper deceleration slope extrapolated to the zero baseline (Fig. 6). Measurements are usually done in 5 to 10 cardiac cycles, with a cycle length equivalent to heart rate of 60 to 80 beats/min. Pulmonary venous DT correlated better with PCWP than transmitral DT in patients with $\mathrm{AF}^{47)}$ Matsukida et al. ${ }^{36)}$ demonstrated that pulmonary venous DT $\leq 150$ ms predicted PCWP $\geq 18 \mathrm{~mm} \mathrm{Hg}$ with $100 \%$ sensitivity and $96 \%$ specificity in patients with AF.

A usage of monitoring PVF is the detection of PV stenosis after RFCA for AF, which occurs in $1 \%$ to $3 \%$ of current series. The PVF measurements using transesophageal echocardiography (TEE) Doppler have allowed the detection of a significant PV stenosis following RFCA if the diagnosis is confined to a combination of elevated peak PV velocity $(\geq 110 \mathrm{~cm} / \mathrm{s})$ with turbulence and little flow variation (Fig. 7). ${ }^{48)}$ In one study, TTE was also available for diagnosing PV stenosis before and after RFCA for AF ${ }^{49)}$ However, it is currently accepted that TTE or TEE are limited by its inability to image deeply into all four PVs and are less useful in establishing the extent and location of PV stenosis. ${ }^{50)}$

\section{ROLE OF TRANSESOPHAGEAL ECHOCARDIOGRAPHY IN AF}

\section{IDENTIFICATION AND RISK STRATIFICATION OF LA/LAA THROMBUS}

The risk of systemic emboli, probably arising in the LA cavity or LAA as a result of circulatory stasis, is an important consideration in AF. AF is considered to be responsible for almost half of all cardiogenic thromboembolism. One of the primary goals of management of patients with $\mathrm{AF}$ is the prevention of thromboembolic events. TTE has a low sensitivity for detection of thrombi in LA and especially LAA. ${ }^{51)}$ TEE provides excellent visualization of posterior cardiac structures and is the modality of choice for detecting LA or LAA thrombi with a sensitivity and specificity of approximately $95 \%$ to $100 \%$ (Fig. 8). ${ }^{52)}$

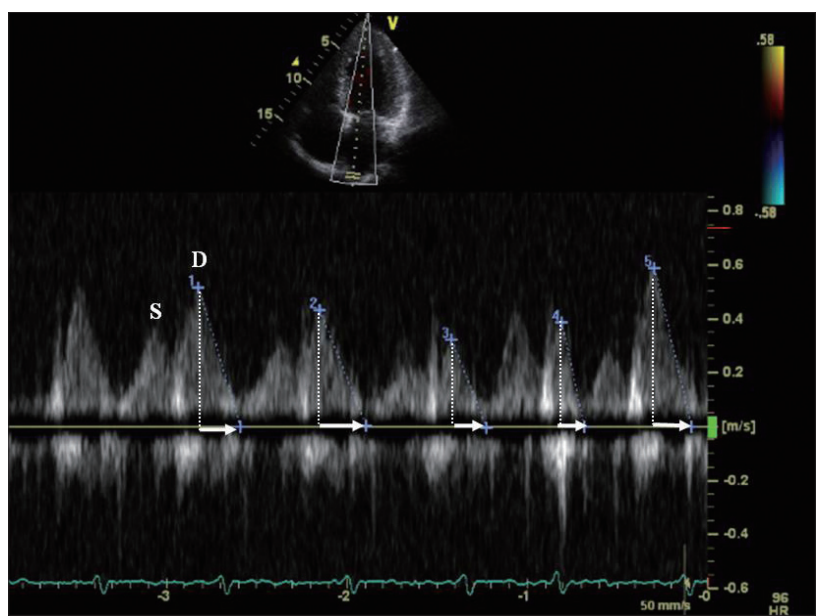

Fig. 6. Pulmonary venous flow pattern demonstrated by transthoracic echocardiography in atrial fibrillation. Arrow indicates pulmonary venous diastolic deceleration time. S: peak systolic velocity, D: peak diastolic velocity.

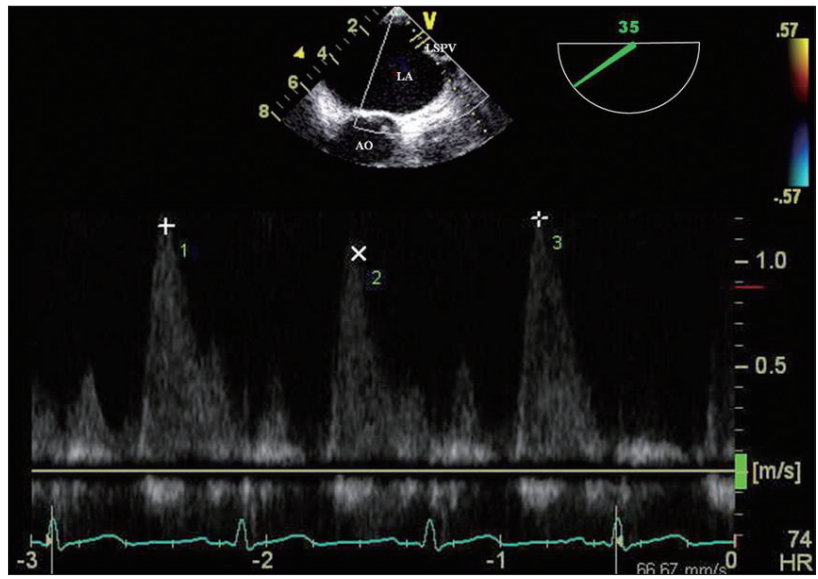

Fig. 7. Transesophageal echocardiography can identify significant pulmonary vein (PV) stenosis. Pulsed-wave Doppler of PV inflow $>110 \mathrm{~cm} / \mathrm{s}$ confirms hemodynamically significant stenosis. LA: left atrium, AO: aorta, LSPV: left superior pulmonary vein.

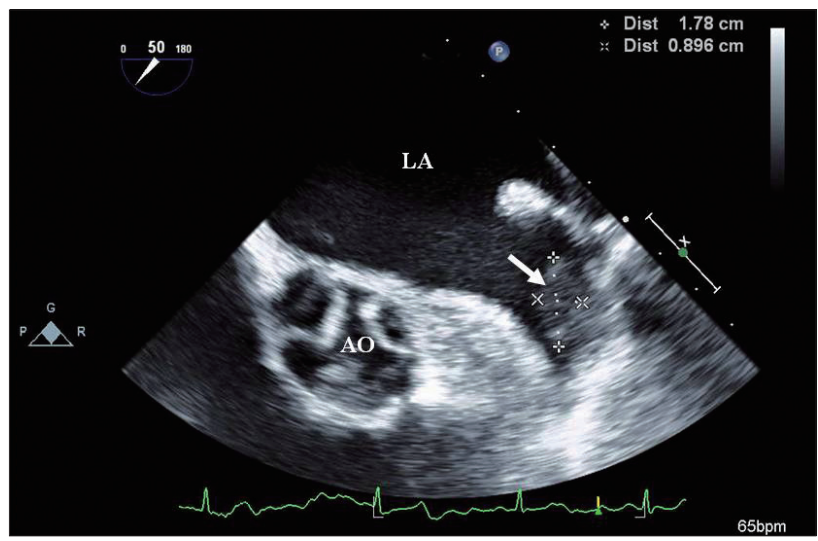

Fig. 8. Image of thrombus (arrow) within the left atrial appendage discovered on a transesophageal echocardiography. LA: left atrium, AO: aorta. 
Thrombus identification is also challenging even if the appendage is visualized adequately. It is difficult to distinguish small thrombi from artifacts, including prominent trabecular structures, duplication artifacts, and adipose tissue within the transverse sinus. It is necessary to attempt to differentiate any suspicious abnormalities from thrombus in multiple views.

In the absence of formed thrombi, a dense SEC has been demonstrated to be a strong predictor of ischemic strokes (Fig. 9). When blood flow velocities are reduced in cardiac chambers and especially in the LAA, "smoke-like" echoes swirling in the cavity may be seen. An annual thromboembolic event

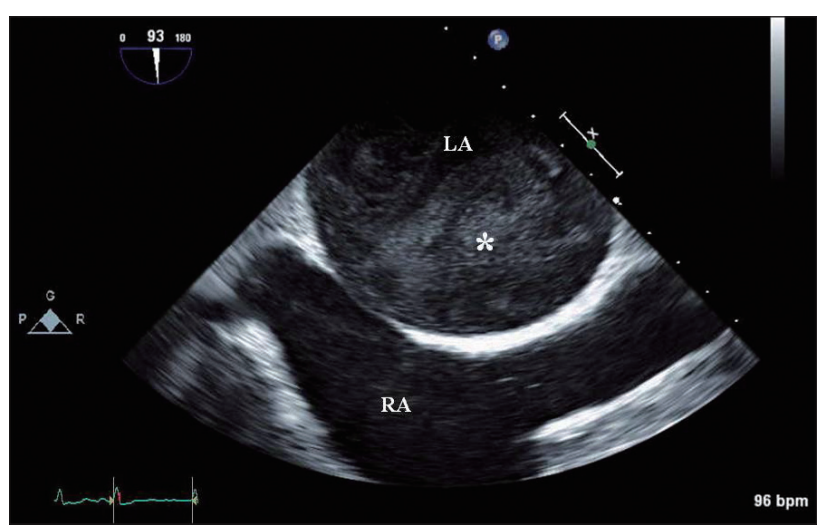

Fig. 9. Spontaneous echo contrast $\left(^{\star}\right)$ swirling detected by transesophageal echocardiography in a patient with atrial fibrillation. LA: left atrium, RA: right atrium.

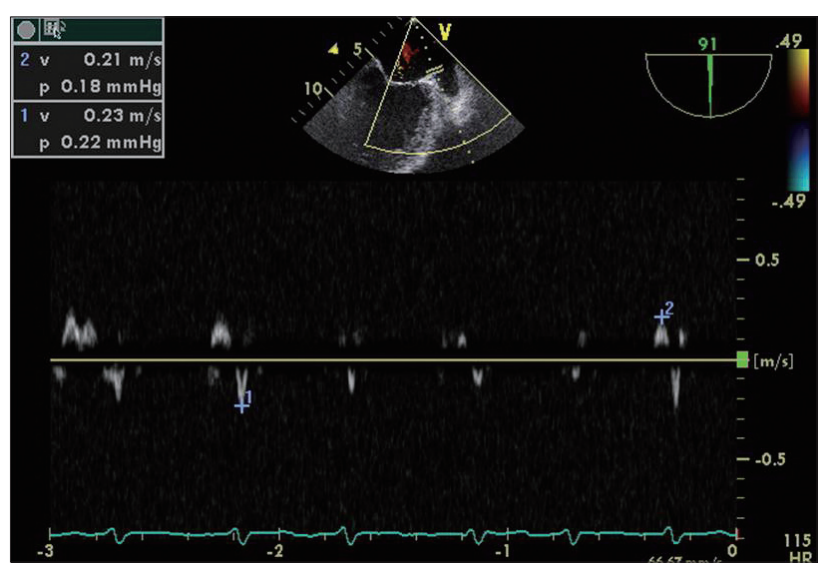

Fig. 10. Pulsed wave Doppler of the left atrial appendage with transesophageal echocardiography. This picture demonstrates the decreased emptying and filling velocities in patients with atrial fibrillation.

Table 1. Clinical and echocardiographic predictors of systemic thromboembolism

Recent history of systemic thromboembolism

Increased atrial size

Left atrial appendage thrombus or sludge

Severe spontaneous echo contrast

Left atrial appendage emptying velocity $<20 \mathrm{~cm} / \mathrm{s}$

Left ventricular systolic dysfunction

Complex aortic atheroma rate of $12 \%$ has been observed in patients with SEC compared to $3 \%$ in patients without it. ${ }^{53)}$ The finding of thrombus on TEE represents a poor outcome. In one study, it was associated with an embolic risk up to $10.4 \%$ per year and a death risk of $15.8 \%$ in a series of patients, most of whom were receiving anticoagulation therapy. ${ }^{54)}$

LAA was sometimes regarded as just a minor extension of the atrium. However, the importance of its function has been brought up because of its contribution to formation of thrombus. The mechanical function of LAA is best assessed with TEE utilizing pulsed wave Doppler measurement of LAA emptying and filling velocities (Fig. 10). In patients with sinus rhythm, LAA contracts once per cardiac cycle, and flow velocities at the ostium demonstrate a biphasic pattern with peak velocities generally exceeding $50 \mathrm{~cm} / \mathrm{s}^{55)}$ Low LAA emptying flow velocities $(<20 \mathrm{~cm} / \mathrm{s})$ in AF correlate strongly with the presence of SEC and thrombus formation, ${ }^{56)}$ whereas LAA emptying flow velocities $>40 \mathrm{~cm} / \mathrm{s}$ predict greater likelihood to remain in sinus rhythm 1 year after successful cardioversion. ${ }^{53)}$ For patients with AF, TEE risk factors of clinical thromboembolism include LAA thrombus, severe SEC, decreased $(<20 \mathrm{~cm} / \mathrm{s}$ ) flow velocities at LAA ostium, and complex aortic plaque (Table 1). ${ }^{56) 57)}$ A TEE performed 3 to 6 months after AF ablation can also evaluate thromboembolic risk and need for long-term anticoagulation, as echocardiographic risk factors may be present even if restoration of sinus rhythm is successful.

In addition to LAA Doppler assessment, measuring LAA area and ejection fraction, TDI, and 3D TEE are emerging as the new complementary techniques. ${ }^{58-60)}$ These are performed rarely, however, and lack of data suggesting additional prognostic value beyond simple flow velocity assessment.

\section{TEE-GUIDED EARLY CARDIOVERSION}

One of the primary goals of therapy in AF is the restoration and maintenance of sinus rhythm, with the aim of reducing symptoms and thromboembolic events. Cardioversion of AF to sinus rhythm can be performed with high rates of immediate success but unfortunately it may be complicated by embolic events in up to $7 \%$ of patients if the procedure is not preceded by several weeks of anticoagulation. ${ }^{6162)}$ Conventional care of patients with AF of prolonged (more than 48 hours) of unknown duration had required that these patients should be treated with oral anticoagulation for at least 7 weeks (3 weeks before and 4 weeks after cardioversion). ${ }^{63)}$ The conventional approach to antithrombotic management before trying cardioversion has several potential disadvantages. This has promoted the recent suggestion of alternative approaches, such as TEE-guided early cardioversion. The advantages of TEE-guided early cardioversion with short term anticoagulation over the conventional strategy include the following: 1) In patients with no thrombus identified by TEE, the total duration of anticoagulation can be reduced by weeks, potentially 
reducing the risk of bleeding. 2) A shorter duration of AF before cardioversion is a strong predictor of AF recurrence following cardioversion. Therefore, early cardioversion with a TEE-guided approach might prevent the atrial remodeling and enable higher rates of sinus conversion and maintenance of sinus rhythm. 3) A TEE-based strategy could lower total costs by limiting laboratory tests, reducing preprocedural bleeding events, and improving clinical outcomes (Table 2).

However, thromboembolic events following cardioversion from $\mathrm{AF}$ were documented among patients with absent or subtherapeutic anticoagulation despite a negative TEE for thrombus ${ }^{6(4)}$ possibly caused by tiny thrombi that are undetected at TEE or as a result of new thrombus formation caused by LA/LAA stunning after cardioversion. ${ }^{24)}$ Therefore, in current practice, TEE-guided early cardioversion includes screening for an existing thrombus and therapeutic anticoagulation at the time of TEE, as well as post-cardioversion anticoagulation prophylaxis to avoid new thrombus formation because of LA or LAA stunning (Fig. 11). The assessment of cardioversion using transesophageal echocardiography (ACUTE) multicenter randomized study demonstrated that embolic events and maintenance of sinus rhythm were similar in the two treatment strategies (conventional vs. TEE-guided early cardioversion), although the rate of hemorrhagic events was lower with the TEE-guided strategy. ${ }^{65)} \mathrm{A}$ new antithrombotic strategy of TEE-guided cardioversion with low molecular weight heparin has been suggested. The ACUTE II pilot study ${ }^{60)}$ and randomized trial, ${ }^{67}$ which compared short-term antithbombotic therapy using low molecular weight heparin (LMWH) with intravenous unfractionated heparin (UFH), showed similar safety and efficacy with a lower length of hospitalization and more sinus rhythm in the LMWH group. In concert with precardioversion therapeutic anticoagulation with UFH, LMWH, or warfarin, TEE-guided early cardioversion is comparable to 4 weeks of precardioversion warfarin with a risk of clinical thromboembolism $<1 \%$. $65-67)$

\section{ROLE OF INTRACARDIAC ECHOCARDIOGRAPHY IN AF}

As mentioned above, RFCA with PV isolation has become as an effective therapy for patients with $\mathrm{AF}^{68)}$ ICE with $2 \mathrm{D}$ and Doppler technique is widely used in the practice of interventional electrophysiology. Advances in catheter-based ultrasound transducers and imaging technology provide more delicate images and enable direct visualization of anatomical structures when performing the RFCA procedures. This technique is quite safe with a negligible rate of complications and good patient tolerance. It allows improvement in success rate and decrease in complication when compared with fluoroscopic approach. ${ }^{69)}$

ICE enables the ready detection of some anatomical variations of LA such as PV and interatrial septal anatomy. Appreciation of these variations is essential to guide positioning of the circular mapping catheter and ablation catheter. Transseptal catheterization is an inevitable process of $\mathrm{PV}$ isolation. Anatomical variations of interatrial septum such as aneurismal septum, double membrane septum, patent foramen ovale, and others make this process complicated. ICE helps visualize the interatrial septum and detect some of the related anatomical variations that could be trouble during transseptal puncture. The use of ICE helps in determining the exact position of tip of the transseptal sheath by looking for tenting of the interatrial septum. The goal of transseptal puncture is to cross the septum in the posterior region of the fossa ovalis. It also enables avoidance of the life-threatening complication, such as perforation of lateral wall of LA or aortic root.

ICE allows for the adequate placement of the circular mapping catheter. Exact positioning and adequate contact of the catheter are very important, because they make delivery of radiofrequency (RF) energy effective and minimize the risk of complications, such as PV stenosis and thrombus formation.

ICE is useful as a monitoring tool for titration of energy

Table 2. Advantages and disadvantages of transesophageal echocardiography-guided early cardioversion
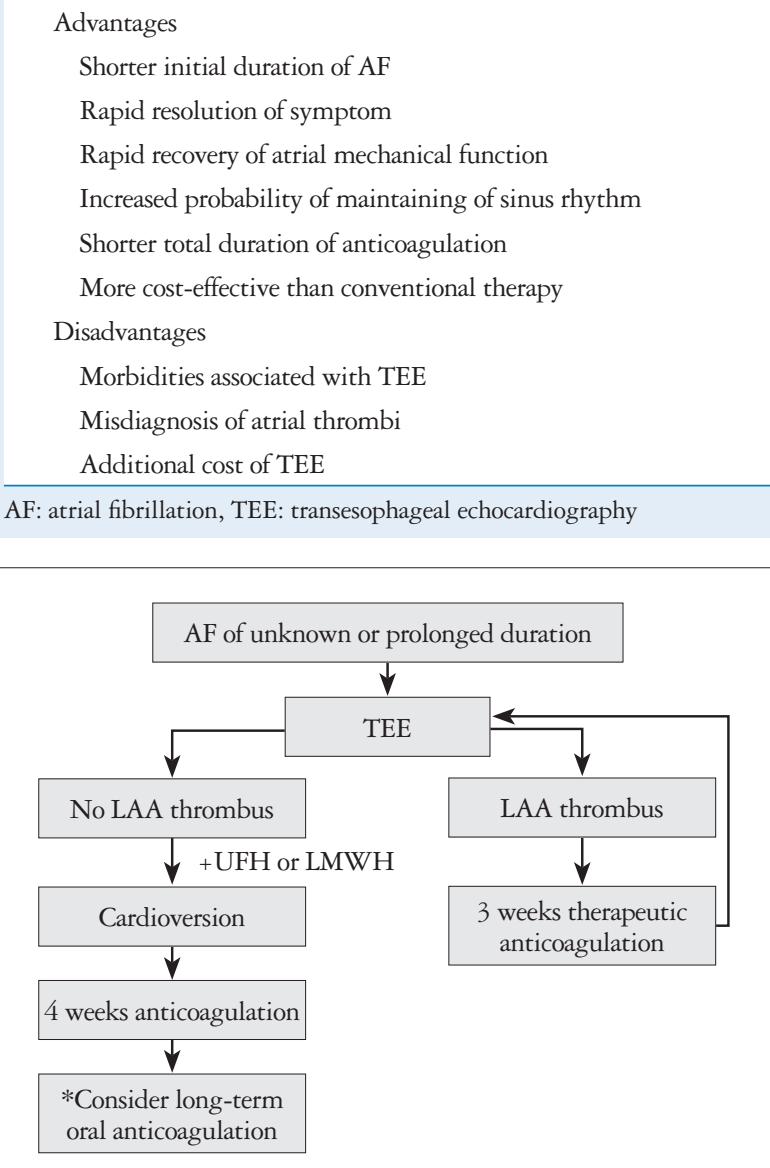

Fig. 11. Schematic flow chart of the transesophageal echocardiographyguided early cardioversion. *Long-term oral anticoagulation if stroke risk factors and/or risk of AF recurrence/presence of thrombus. AF: atrial fibrillation, LAA: left atrial appendage, UFH: unfractionated heparin, LMWH: low molecular weight heparin. 
power and/or duration. It can control lesion formation and prevent tissue overheating or structural perforation. Conventionally, temperature, power, and impedance are monitored during RF energy delivery. The appearance of microbubbles resulting from superheating can even precede increased impedance. ${ }^{70)}$ Ablation needs to be terminated immediately if a sudden appearance of microbubbles is observed. This can prevent tissue damage and scar formation which may promote PV stenosis, LA perforation, or pericardial effusion. ${ }^{71)}$

ICE also allows early identification of complications related with procedure including damage to intracardiac structures, thrombus formation, $\mathrm{PV}$ stenosis, and pericardial effusion during RFCA.

ICE plays a valuable role during electrophysiologic procedures. Since it provides a lot of information about the intracardiac structures and hemodynamic assessments, ICE is expected to be used widely in clinical practice in the near future.

\section{OTHER IMAGING MODALITIES IN MANAGEMENT OF AF}

Other imaging modalities such as multidetector computed tomography (MDCT) and magnetic resonance imaging (MRI) provide more accurate measurement and better understanding of the cardiac anatomy, especially anatomical variations of $\mathrm{PV}$ and LA before RFCA of AF. ${ }^{7273)}$ MDCT and MRI have the additional advantage that it is operator-independent, unlike TTE, TTE, and ICE. As mentioned above, MDCT and MRI provide the best tests for evaluation of PV stenosis after RFCA of $\mathrm{AF}^{50)}$

MDCT provides so high quality images of entire LA and each PV that these images are used with the electroanatomical mapping system to help guide the safe and effective RFCA of $\mathrm{AF}$ (Fig. 12) ${ }^{74775)} \mathrm{MDCT}$ is increasingly being used to exclude thrombus and shows excellent negative predictive value. ${ }^{76)}$ Another advantage of MDCT is that it enables to identify the

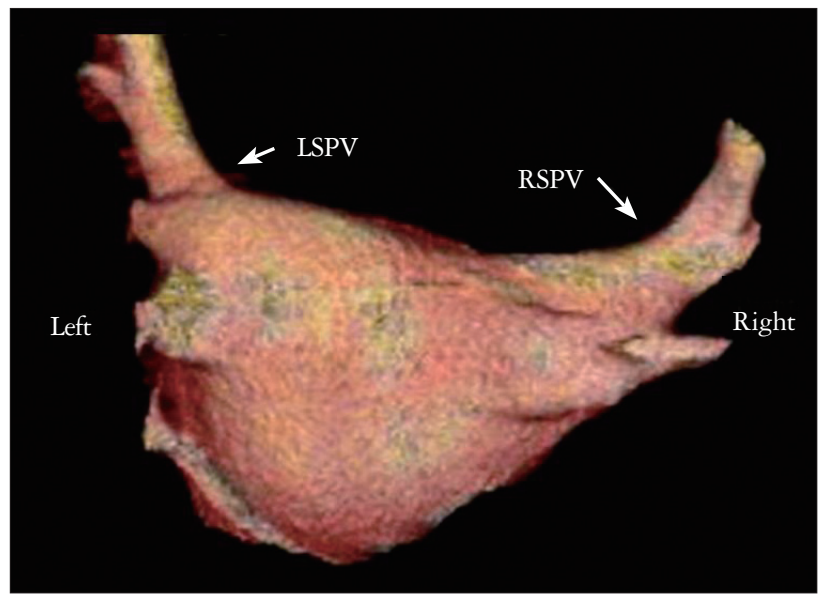

Fig. 12. The posterior view of computed tomography image shows three-dimensional information of anatomy of left atrium and pulmonary vein. LSPV: left superior pulmonary vein, RSPV: right superior pulmonary vein. extracardiac abnormalities, including pulmonary nodule, lung parenchymal disease, pleural abnormalities, hepatic problems, and others. ${ }^{77)}$

AF promotes atrial remodeling, resulting in the loss of atrial myocytes and increased collagen deposit and hence fibrosis of the LA wall. ${ }^{78)}$ Delayed-enhancement MRI using gadolinium contrast is a novel noninvasive method to detect and evaluate the degree of remodeling or fibrosis associated with AF in the LA tissue. ${ }^{79)}$ An increased amount of enhancement within the LA seems to be associated with AF recurrence after RFCA. ${ }^{79)}$

MDCT and MRI are promising tools for management of $\mathrm{AF}$, however, radiation exposure and very high cost are the problem, respectively. Furthermore, it takes too long to examine and acquire images with these imaging modalities. Although clinical trials of pacemakers with new designs and protocols are underway, the risk of performing MRI in the presence of a permanent pacemaker or implantable cardioverter-defibrillator is still present in clinical fields. Therefore, adequate combination of the various imaging modalities allows for the proper management of patient with AF effectively.

\section{CONCLUSION}

Because of the easy-accessibility, none or less-invasiveness, no radiation hazard, and few contraindications, both TTE and TEE are valuable tools that can provide cardiac anatomical and functional information. The advantages of echocardiography assist in the risk stratification, diagnosis of complications, and management of anticoagulation in patients with AF. The novel technique of ICE plays an important role during percutaneous interventional electrophysiology. MDCT and MRI have complementary role to echocardiography in the management of AF.

Ongoing advances in imaging acquisition and analysis in echocardiography will make the echocardiography more popular for evaluating and management of patients with AF.

\section{REFERENCES}

1. Peters NS, Schilling RJ, Kanagaratnam P, Markides V. Atrial fibrillation: strategies to control, combat, and cure. Lancet 2002;359:593-603.

2. Go AS, Hylek EM, Phillips KA, Chang Y, Henault LE, Selby JV, Singer DE. Prevalence of diagnosed atrial fibrillation in adults: national implications for rhythm management and stroke prevention: the AnTicoagulation and Risk Factors in Atrial Fibrillation (ATRIA) Study. JAMA 2001;285:2370-5.

3. Lloyd-Jones DM, Wang TJ, Leip EP, Larson MG, Levy D, Vasan RS, D’Agostino RB, Massaro JM, Beiser A, Wolf PA, Benjamin EJ. Lifetime risk for development of atrial fibrillation: the Framingham Heart Study. Circulation 2004;110:1042-6.

4. Vaziri SM, Larson MG, Benjamin EJ, Levy D. Echocardiographic predictors of nonrheumatic atrial fibrillation. The Framingham Heart Study. Circulation 1994;89:724-30.

5. Fuster V, Rydén LE, Asinger RW, Cannom DS, Crijns HJ, Frye RL, Halperin JL, Kay GN, Klein WW, Lévy S, McNamara RL, Prystowsky EN, Wann LS, Wyse DG, Gibbons RJ, Antman EM, Alpert JS, Faxon DP, Fuster V, Gregoratos G, Hiratzka LF, Jacobs AK, 
Russell RO, Smith SC Jr, Klein WW, Alonso-Garcia A, Blomström-Lundqvist $\mathrm{C}$, de Backer $\mathrm{G}$, Flather M, Hradec J, Oto A, Parkhomenko A, Silber S, Torbicki A; American College of Cardiology/American Heart Association Task Force on Practice Guidelines; European Society of Cardiology Committee for Practice Guidelines and Policy Conferences (Committee to Develop Guidelines for the Management of Patients With Atrial Fibrillation); North American Society of Pacing and Electrophysiology. ACC/ AHA/ESC Guidelines for the Management of Patients With Atrial Fibrillation: Executive Summary A Report of the American College of Cardiology/American Heart Association Task Force on Practice Guidelines and the European Society of Cardiology Committee for Practice Guidelines and Policy Conferences (Committee to Develop Guidelines for the Management of Patients With Atrial Fibrillation) Developed in Collaboration With the North American Society of Pacing and Electrophysiology. Circulation 2001;104:2118-50.

6. Lester SJ, Ryan EW, Schiller NB, Foster E. Best method in clinical practice and in research studies to determine left atrial size. Am J Cardiol 1999;84:829-32.

7. Lang RM, Bierig M, Devereux RB, Flachskampf FA, Foster E, Pellikka PA, Picard MH, Roman MJ, Seward J, Shanewise JS, Solomon SD, Spencer KT, Sutton MS, Stewart WJ; Chamber Quantification Writing Group; American Society of Echocardiography's Guidelines and Standards Committee; European Association of Echocardiography. Recommendations for chamber quantification: a report from the American Society of Echocardiography's Guidelines and Standards Committee and the Chamber Quantification Writing Group, developed in conjunction with the European Association of Echocardiography, a branch of the European Society of Cardiology. J Am Soc Echocardiogr 2005;18: 1440-63.

8. Abhayaratna WP, Seward JB, Appleton CP, Douglas PS, Oh JK, Tajik AJ, Tsang TS. Left atrial size: physiologic determinants and clinical applications. J Am Coll Cardiol 2006;47:2357-63.

9. Jenkins C, Bricknell K, Marwick TH. Use of real-time three-dimensional echocardiography to measure left atrial volume: comparison with other echocardiographic techniques. J Am Soc Echocardiogr 2005;18:991-7.

10. Benjamin EJ, D’Agostino RB, Belanger AJ, Wolf PA, Levy D. Left atrial size and the risk of stroke and death. The Framingham Heart Study. Circulation 1995;92:835-41.

11. Tani T, Tanabe K, Ono M, Yamaguchi K, Okada M, Sumida T, Konda T, Fujii Y, Kawai J, Yagi T, Sato M, Ibuki M, Katayama M, Tamita K, Yamabe K, Yamamuro A, Nagai K, Shiratori K, Morio$\mathrm{ka}$ S. Left atrial volume and the risk of paroxysmal atrial fibrillation in patients with hypertrophic cardiomyopathy. J Am Soc Echocardiogr 2004:17:644-8.

12. Beinart R, Boyko V, Schwammenthal E, Kuperstein R, Sagie A, Hod H, Matetzky S, Behar S, Eldar M, Feinberg MS. Long-term prognostic significance of left atrial volume in acute myocardial infarction. $J$ Am Coll Cardiol 2004;44:327-34.

13. Psaty BM, Manolio TA, Kuller LH, Kronmal RA, Cushman M, Fried LP, White R, Furberg CD, Rautaharju PM. Incidence of and risk factors for atrial fibrillation in older adults. Circulation 1997;96:2455-61.

14. Tsang TS, Abhayaratna WP, Barnes ME, Miyasaka Y, Gersh BJ, Bailey KR, Cha SS, Seward JB. Prediction of cardiovascular outcomes with left atrial size: is volume superior to area or diameter? J Am Coll Cardiol 2006;47:1018-23.

15. Brodsky MA, Allen BJ, Capparelli EV, Luckett CR, Morton R, Henry WL. Factors determining maintenance of sinus rhythm after chronic atrial fibrillation with left atrial dilatation. Am J Cardiol 1989;63: 1065-8.

16. Dittrich HC, Erickson JS, Schneiderman T, Blacky AR, Savides T, Nicod PH. Echocardiographic and clinical predictors for outcome of elective cardioversion of atrial fibrillation. Am J Cardiol 1989;63:193-7.

17. Shin SH, Park MY, Oh WJ, Hong SJ, Pak HN, Song WH, Lim DS, Kim YH, Shim WJ. Left atrial volume is a predictor of atrial fibrillation recurrence after catheter ablation. J Am Soc Echocardiogr 2008;21: 697-702.

18. Van Gelder IC, Crijns HJ, Van Gilst WH, Hamer HP, Lie KI. Decrease of right and left atrial sizes after direct-current electrical cardioversion in chronic atrial fibrillation. Am J Cardiol 1991;67:93-5.

19. Reant P, Lafitte S, Jaïs P, Serri K, Weerasooriya R, Hocini M, Pillois $\mathrm{X}$, Clementy J, Haïssaguerre M, Roudaut R. Reverse remodeling of the left cardiac chambers after catheter ablation after 1 year in a series of patients with isolated atrial fibrillation. Circulation 2005;112:2896-903.

20. Stefanadis C, Dernellis J, Stratos C, Tsiamis E, Tsioufis C, Toutouzas K, Vlachopoulos C, Pitsavos C, Toutouzas P. Assessment of left atrial pressure-area relation in humans by means of retrograde left atrial catheterization and echocardiographic automatic boundary detection: effects of dobutamine. J Am Coll Cardiol 1998;31:426-36.

21. Choong CY, Herrmann HC, Weyman AE, Fifer MA. Preload dependence of Doppler-derived indexes of left ventricular diastolic function in bumans. J Am Coll Cardiol 1987;10:800-8.

22. Manning WJ, Silverman DI, Katz SE, Riley MF, Doherty RM, Munson JT, Douglas PS. Temporal dependence of the return of atrial mechanical function on the mode of cardioversion of atrial fibrillation to sinus rhythm. Am J Cardiol 1995;75:624-6.

23. Thomas L, Thomas SP, Hoy M, Boyd A, Schiller NB, Ross DL. Comparison of left atrial volume and function after linear ablation and after cardioversion for chronic atrial fibrillation. Am J Cardiol 2004;93:165-70.

24. Manning WJ, Silverman DI, Katz SE, Riley MF, Come PC, Doherty RM, Munson JT, Douglas PS. Impaired left atrial mechanical function after cardioversion: relation to the duration of atrial fibrillation. $J$ Am Coll Cardiol 1994;23:1535-40.

25. Sohn DW, Chai IH, Lee DJ, Kim HC, Kim HS, Oh BH, Lee MM, Park YB, Choi YS, Seo JD, Lee YW. Assessment of mitral annulus velocity by Doppler tissue imaging in the evaluation of left ventricular diastolic function. J Am Coll Cardiol 1997;30:474-80.

26. Thomas L, Levett K, Boyd A, Leung DY, Schiller NB, Ross DL. Changes in regional left atrial function with aging: evaluation by Doppler tissue imaging. Eur J Echocardiogr 2003;4:92-100.

27. Hesse B, Schuele SU, Thamilasaran M, Thomas J, Rodriguez L. A rapid method to quantify left atrial contractile function: Doppler tissue imaging of the mitral annulus during atrial systole. Eur J Echocardiogr 2004;5:86-92.

28. Wang T, Wang M, Fung JW, Yip GW, Zhang Y, Ho PP, Tse DM, $\mathrm{Yu}$ CM, Sanderson JE. Atrial strain rate echocardiography can predict success or failure of cardioversion for atrial fibrillation: a combined transthoracic tissue Doppler and transoesophageal imaging study. Int J Cardiol 2007;114:202-9.

29. Di Salvo G, Caso P, Lo Piccolo R, Fusco A, Martiniello AR, Russo MG, D’Onofrio A, Severino S, Calabró P, Pacileo G, Mininni N, Calabró R. Atrial myocardial deformation properties predict maintenance of sinus rhythm after external cardioversion of recent-onset lone atrial fibrillation: a color Doppler myocardial imaging and transthoracic and transesophageal echocardiographic study. Circulation 2005;112:387-95.

30. Hwang HJ, Choi EY, Rhee SJ, Joung B, Lee BH, Lee SH, Kim J, Lee MH, Jang Y, Chung N, Kim SS. Left atrial strain as predictor of successful outcomes in catheter ablation for atrial fibrillation: a two-dimensional myocardial imaging study. J Interv Card Electrophysiol 2009;26:127-32.

31. Thomas L, McKay T, Byth K, Marwick TH. Abnormalities of left atrial function after cardioversion: an atrial strain rate study. Heart 2007;93:89-95.

32. Thomas L, Hoy M, Byth K, Schiller NB. The left atrial function index: a rhythm independent marker of atrial function. Eur J Echocardiogr 
2008;9:356-62.

33. Wang TJ, Larson MG, Levy D, Vasan RS, Leip EP, Wolf PA, D’Agostino RB, Murabito JM, Kannel WB, Benjamin EJ. Temporal relations of atrial fibrillation and congestive heart failure and their joint influence on mortality: the Framingham Heart Study. Circulation 2003;107:2920-5.

34. Nagueh SF, Kopelen HA, Quiñones MA. Assessment of left ventricular filling pressures by Doppler in the presence of atrial fibrillation. Circulation 1996;94:2138-45.

35. Temporelli PL, Scapellato F, Corrà U, Eleuteri E, Imparato A, Giannuzzi P. Estimation of pulmonary wedge pressure by transmitral Doppler in patients with chronic heart failure and atrial fibrillation. Am J Cardiol 1999;83:724-7.

36. Matsukida K, Kisanuki A, Toyonaga K, Murayama T, Nakashima H, Kumanohoso T, Yoshifuku S, Saigo M, Abe S, Hamasaki S, Otsuji Y, Minagoe S, Tei C. Comparison of transthoracic Doppler echocardiography and natriuretic peptides in predicting mean pulmonary capillary wedge pressure in patients with chronic atrial fibrillation. J Am Soc Echocardiogr 2001;14:1080-7.

37. Nagueh SF, Sun H, Kopelen HA, Middleton KJ, Khoury DS. Hemodynamic determinants of the mitral annulus diastolic velocities by tissue Doppler. J Am Coll Cardiol 2001;37:278-85.

38. Ommen SR, Nishimura RA, Appleton CP, Miller FA, Oh JK, Redfield MM, Tajik AJ. Clinical utility of Doppler echocardiography and tissue Doppler imaging in the estimation of left ventricular filling pressures: A comparative simultaneous Doppler-catheterization study. Circulation 2000;102:1788-94.

39. Park HS, Naik SD, Aronow WS, Visintainer PF, Das M, McClung JA, Belkin RN. Differences of lateral and septal mitral annulus velocity by tissue Doppler imaging in the evaluation of left ventricular diastolic function. Am J Cardiol 2006;98:970-2.

40. Sohn DW, Song JM, Zo JH, Chai IH, Kim HS, Chun HG, Kim HC. Mitral annulus velocity in the evaluation of left ventricular diastolic function in atrial fibrillation. J Am Soc Echocardiogr 1999;12:927-31.

41. Khouri SJ, Maly GT, Suh DD, Walsh TE. A practical approach to the echocardiographic evaluation of diastolic function. J Am Soc Echocardiogr 2004; 17:290-7.

42. Garcia MJ, Thomas JD, Klein AL. New Doppler echocardiographic applications for the study of diastolic function. J Am Coll Cardiol 1998;32: 865-75.

43. Bollmann A, Binias KH, Grothues F, Schwerdtfeger A, Klein HU. Left atrial appendage function and pulmonary venous flow in patients with nonrheumatic atrial fibrillation and their relation to spontaneous echo contrast. Echocardiography 2002;19:37-43.

44. Okçün B, Yigit Z, Küçükoglu MS, Mutlu H, Sansoy V, Güzelsoy D, Uner S. Predictors for maintenance of sinus rhythm after cardioversion in patients with nonvalvular atrial fibrillation. Echocardiography 2002; 19:351-7.

45. Paraskevaidis IA, Theodorakis GN, Katritsis DG, Tsiapras DP, Livanis EG, Kremastinos DT. Pulmonary vein flow analysis by transoesophageal echocardiogr phy in patients with chronic atrial fibrillation; 1 year follow-up after cardioversion. Eur Heart J 1999;20:375-85.

46. Donal E, Grimm RA, Yamada H, Kim YJ, Marrouche N, Natale A, Thomas JD. Usefulness of Doppler assessment of pulmonary vein and left atrial appendage flow following pulmonary vein isolation of chronic atrial fibrillation in predicting recovery of left atrial function. Am J Cardiol 2005;95:941-7.

47. Chirillo F, Brunazzi MC, Barbiero M, Giavarina D, Pasqualini M, Franceschini-Grisolia E, Cotogni A, Cavarzerani A, Rigatelli G, Stritoni P, Longhini C. Estimating mean pulmonary wedge pressure in patients with chronic atrial fibrillation from transthoracic Doppler indexes of mitral and pulmonary venous flow velocity. J Am Coll Cardiol 1997;30:19-26.
48. Jander N, Minners J, Arentz T, Görnandt L, Fürmaier R, Kalusche $\mathrm{D}$, Neumann FJ. Transesophageal echocardiography in comparison with magnetic resonance imaging in the diagnosis of pulmonary vein stenosis after radiofrequency ablation therapy. J Am Soc Echocardiogr 2005;18:654-9.

49. Lee DH, Oh YS, Shin WS, Kim JH, Choi YS, Jang SW, Park CS, Youn HJ, Lee MY, Chung WS, Seung KB, Rho TH, Kim JH, Choi KB. A transthoracic echocardiographic follow-up study after catheter ablation of atrial fibrillation: can we detect pulmonary vein stenosis by transthoracic echocardiography? Korean Circ J 2010;40:442-7.

50. Holmes DR Jr, Monahan KH, Packer D. Pulmonary vein stenosis complicating ablation for atrial fibrillation: clinical spectrum and interventional considerations. JACC Cardiovasc Interv 2009;2:267-76.

51. Omran H, Jung W, Rabahieh R, Wirtz P, Becher H, Illien S, Schimpf R, Lüderitz B. Imaging of thrombi and assessment of left atrial appendage function: a prospective study comparing transthoracic and transoesophageal echocardiography. Heart 1999;81:192-8.

52. Klein AL, Murray RD, Grimm RA. Role of transesophageal echocardiography-guided cardioversion of patients with atrial fibrillation. $J \mathrm{Am}$ Coll Cardiol 2001;37:691-704.

53. Leung DY, Black IW, Cranney GB, Hopkins AP, Walsh WF. Prognostic implications of left atrial spontaneous echo contrast in nonvalvular atrial fibrillation. J Am Coll Cardiol 1994;24:755-62.

54. Leung DY, Davidson PM, Cranney GB, Walsh WF. Thromboembolic risks of left atrial thrombus detected by transesophageal echocardiogram. Am J Cardiol 1997;79:626-9.

55. Jue J, Winslow T, Fazio G, Redberg RF, Foster E, Schiller NB. Pulsed Doppler characterization of left atrial appendage flow. J Am Soc Echocardiogr 1993;6:237-44.

56. Transesophageal echocardiographic correlates of thromboembolism in highrisk patients with nonvalvular atrial fibrillation. The Stroke Prevention in Atrial Fibrillation Investigators Committee on Echocardiography. Ann Intern Med 1998;128:639-47.

57. Blackshear JL, Pearce LA, Hart RG, Zabalgoitia M, Labovitz A, Asinger RW, Halperin JL. Aortic plaque in atrial fibrillation: prevalence, predictors, and thromboembolic implications. Stroke 1999;30:834-40.

58. Agmon Y, Khandheria BK, Gentile F, Seward JB. Echocardiographic assessment of the left atrial appendage. J Am Coll Cardiol 1999;34: 1867-77.

59. Sahin T, Ural D, Kilic T, Bildirici U, Kozdag G, Agacdiken A, Ural E. Evaluation of left atrial appendage functions according to different etiologies of atrial fibrillation with a tissue Doppler imaging technique by using transesophageal echocardiography. Echocardiography 2009;26:171-81.

60. Nakajima H, Seo Y, Ishizu T, Yamamoto M, Machino T, Harimura Y, Kawamura R, Sekiguchi Y, Tada H, Aonuma K. Analysis of the left atrial appendage by three-dimensional transesophageal echocardiography. Am J Cardiol 2010;106:885-92.

61. Weinberg DM, Mancini J. Anticoagulation for cardioversion of atrial fibrillation. Am J Cardiol 1989;63:745-6.

62. Arnold AZ, Mick MJ, Mazurek RP, Loop FD, Trohman RG. Role of prophylactic anticoagulation for direct current cardioversion in patients with atrial fibrillation or atrial flutter. J Am Coll Cardiol 1992;19:851-5.

63. Singer DE, Albers GW, Dalen JE, Go AS, Halperin JL, Manning WJ. Antithrombotic therapy in atrial fibrillation: the Seventh ACCP Conference on Antithrombotic and Thrombolytic Therapy. Chest 2004;126: 429S-56S.

64. Black IW, Fatkin D, Sagar KB, Khandheria BK, Leung DY, Galloway JM, Feneley MP, Walsh WF, Grimm RA, Stollberger C, et al. Exclusion of atrial thrombus by transesophageal echocardiography does not preclude embolism after cardioversion of atrial fibrillation. A multicenter study. Circulation 1994;89:2509-13.

65. Klein AL, Grimm RA, Murray RD, Apperson-Hansen C, Asinger RW, Black IW, Davidoff R, Erbel R, Halperin JL, Orsinelli DA, Por- 
ter TR, Stoddard MF; Assessment of Cardioversion Using Transesophageal Echocardiography Investigators. Use of transesophageal echocardiography to guide cardioversion in patients with atrial fibrillation. $N$ Engl J Med 2001;344:1411-20.

66. Murray RD, Shah A, Jasper SE, Goodman A, Deitcher SR, Katz WE, Malouf JF, Stoddard MF, Grimm RA, Klein AL; ACUTE II pilot study. Transesophageal echocardiography guided enoxaparin antithrombotic strategy for cardioversion of atrial fibrillation: the ACUTE II pilot study. Am Heart J 2000;139:E1-7.

67. Klein AL, Jasper SE, Katz WE, Malouf JF, Pape LA, Stoddard MF, Apperson-Hansen C, Lieber EA; ACUTE II Steering and Publications Committe for the ACUTE II Investigators. The use of enoxaparin compared with unfractionated heparin for short-term antithrombotic therapy in atrial fibrillation patients undergoing transoesophageal echocardiography-guided cardioversion: assessment of Cardioversion Using Transoesophageal Echocardiography (ACUTE) II randomized multicentre study. Eur Heart J 2006;27:2858-65.

68. Haïssaguerre M, Jaïs P, Shah DC, Takahashi A, Hocini M, Quiniou G, Garrigue S, Le Mouroux A, Le Métayer P, Clémenty J. Spontaneous initiation of atrial fibrillation by ectopic beats originating in the pulmonary veins. N Engl J Med 1998;339:659-66.

69. Marrouche NF, Martin DO, Wazni O, Gillinov AM, Klein A, Bhargava M, Saad E, Bash D, Yamada H, Jaber W, Schweikert R, Tchou P, Abdul-Karim A, Saliba W, Natale A. Phased-array intracardiac echocardiography monitoring during pulmonary vein isolation in patients with atrial fibrillation: impact on outcome and complications. Circulation 2003;107:2710-6.

70. Ren JF, Marchlinski FE. Utility of intracardiac echocardiography in left heart ablation for tachyarrhythmias. Echocardiography 2007;24:533-40.

71. Saliba W, Thomas J. Intracardiac echocardiography during catheter ablation of atrial fibrillation. Europace 2008;10 Suppl 3:iii42-7.

72. Schwartzman D, Lacomis J, Wigginton WG. Characterization of left atrium and distal pulmonary vein morphology using multidimensional computed tomography. J Am Coll Cardiol 2003;41:1349-57.
73. Mansour M, Holmvang G, Sosnovik D, Migrino R, Abbara S, Ruskin J, Keane D. Assessment of pulmonary vein anatomic variability by magnetic resonance imaging: implications for catheter ablation techniques for atrial fibrillation. J Cardiovasc Electrophysiol 2004;15:387-93.

74. Dong J, Calkins H, Solomon SB, Lai S, Dalal D, Lardo AC, Brem E, Preiss A, Berger RD, Halperin H, Dickfeld T. Integrated electroanatomic mapping with three-dimensional computed tomographic images for real-time guided ablations. Circulation 2006;113:186-94.

75. Sra J, Narayan G, Krum D, Malloy A, Cooley R, Bhatia A, Dhala A, Blanck Z, Nangia V, Akhtar M. Computed tomography-fluoroscopy image integration-guided catheter ablation of atrial fibrillation. J Cardiovasc Electrophysiol 2007;18:409-14.

76. Schietinger BJ, Bozlar U, Hagspiel KD, Norton PT, Greenbaum HR, Wang H, Isbell DC, Patel RA, Ferguson JD, Gay SB, Kramer CM, Mangrum JM. The prevalence of extracardiac findings by multidetector computed tomography before atrial fibrillation ablation. Am Heart $J$ 2008;155:254-9.

77. Boldt A, Wetzel U, Lauschke J, Weigl J, Gummert J, Hindricks G, Kottkamp H, Dhein S. Fibrosis in left atrial tissue of patients with atrial fibrillation with and without underlying mitral valve disease. Heart 2004:90:400-5.

78. Kim YY, Klein AL, Halliburton SS, Popovic ZB, Kuzmiak SA, Sola S, Garcia MJ, Schoenhagen P, Natale A, Desai MY. Left atrial appendage filling defects identified by multidetector computed tomography in patients undergoing radiofrequency pulmonary vein antral isolation: a comparison with transesophageal echocardiography. Am Heart J 2007;154: 1199-205.

79. Oakes RS, Badger TJ, Kholmovski EG, Akoum N, Burgon NS, Fish EN, Blauer JJ, Rao SN, DiBella EV, Segerson NM, Daccarett M, Windfelder J, McGann CJ, Parker D, MacLeod RS, Marrouche NF. Detection and quantification of left atrial structural remodeling with delayed-enhancement magnetic resonance imaging in patients with atrial fibrillation. Circulation 2009;119:1758-67. 